Mens

revue d'histoire intellectuelle de l'Amérique française

\title{
Réponse de Ramsay Cook à Yvan Lamonde
}

\section{Ramsay Cook}

Volume 11, numéro 1, automne 2010

URI : https://id.erudit.org/iderudit/1023340ar

DOI : https://doi.org/10.7202/1023340ar

Aller au sommaire du numéro

Éditeur(s)

Centre de recherche en civilisation canadienne-française

ISSN

1492-8647 (imprimé)

1927-9299 (numérique)

Découvrir la revue

Citer ce document

Cook, R. (2010). Réponse de Ramsay Cook à Yvan Lamonde. Mens, 11(1), 99-101. https://doi.org/10.7202/1023340ar d'utilisation que vous pouvez consulter en ligne.

https://apropos.erudit.org/fr/usagers/politique-dutilisation/ 
" imaginaires ", de " fragments " postmodernes, de navire sans ancre, de navire à la dérive ? Pour bien comprendre le propos de R. Cook, je souhaiterais qu'il m'éclaire éventuellement en répondant à la question suivante : y a-t-il une mémoire historique dans le multiculturalisme ou son absence est-elle la condition d'existence de celui-ci ?

\section{Réponse de Ramsay Cook à Yvan Lamonde}

Je tenterai de répondre brièvement, peut-être trop brièvement même, aux importantes questions soulevées par Yvan Lamonde dans sa réponse à ma recension de son ouvrage Historien et citoyen.

$\mathrm{Par}$ " présentisme », je fais référence à la téléologie implicite dans toute histoire nationale. Présupposer que les communautés possèdent des identités collectives qui évoluent naturellement vers le cadre national - que la finalité de cette évolution est donc connue d'avance - détermine les questions qui sont posées au passé et les jugements qui sont portés à son égard. Une grande partie des historiographies canadienne, canadienne-française et québécoise illustre, je crois, cette approche téléologique. Trop souvent les historiens "imagine the past and remember the future", pour reprendre l'expression de l'historien britannique Sir Lewis Namier. À tout le moins, l'histoire racontée aux Canadiens et aux Québécois a longtemps laissé dans l'ombre de grands pans du passé, si ce n'est la plus grande part, comme nous l'ont révélé les récentes générations d'historiens.

Parallèlement, il ne fait aucun doute que le concept de " colonialisme " permet de comprendre à la fois l'histoire de la NouvelleFrance et, d'une manière plus complexe et changeante, celle du Canada (aussi bien francophone qu'anglophone) de 1763 aux années 1920 - peut-être même à 1931. Après cette date, le statut autonome formellement concédé au Canada a su satisfaire aussi bien les Canadiens français que les Canadiens anglais. Ce qui est vrai pour 
le Canada au sein de l'Empire britannique vaut aussi pour le Québec au sein du Canada. Les nationalistes n'ont peut-être pas approuvé le nouveau statut du Canada, mais ni Raymond Barbeau dans Le Québec est-il une colonie? (Les Éditions de l'Homme, 1962) ni André d'Allemagne dans Le Colonialisme au Québec (Les Éditions R.-B., 1966) n’ont pu démontrer de manière convaincante que le Québec était encore une colonie dans les années 1960, au sens généralement accordé à ce terme. En suggérant que le Québec devait être décolonisé à la Ralph Waldo Emerson, on confond fallacieusement modernisation et décolonisation, créant ainsi une confusion dérivant d'une erreur téléologique.

L'enjeu le plus complexe soulevé par Lamonde est celui de la mémoire historique. Le rapport entre passé, mémoire et histoire est à la fois subtil et controversé. J'en ai discuté dans un article publié dans la Revue d'études canadiennes/Journal of Canadian Studies (vol. 38, $\mathrm{n}^{\circ} 2$ (printemps 2004), p. 172-178). Selon moi, loin d'être identiques, la mémoire historique et l' histoire sont fondamentalement différentes. Dans son ouvrage The Holocaust in American Life (Houghton Mifflin, 1999), l'historien Peter Novick a bien résumé cette différence, allant jusqu'à démontrer que ces deux approches sont presque contraires : "Collective memory simplifies; sees events from a single, committed perspective; is impatient with ambiguities of any kind; reduces events to mythic archetypes. "C'est cette distinction qu'Ernest Renan avait en tête lorsqu'il a écrit dans son célèbre essai intitulé Qu'est-ce qu'une Nation? (Calman Lévy, 1882) que « [1]'oubli, et je dirai même l'erreur historique, sont un facteur essentiel de la formation d'une nation, et c'est ainsi que le progrès des études historiques est souvent pour la nationalité un danger ". (Pour une illustration provocante de cette affirmation, voir Shlomo Sand, The Invention of the Jewish People (Verso Books, 2010)).

En réponse à la dernière question de Lamonde, je crois que le «multiculturalisme " deviendra éventuellement partie intégrante de notre " mémoire historique" (certains de ses mythes les plus 
importants sont déjà évidents en français comme en anglais). Mais ce multiculturalisme aura aussi son histoire si les historiens font leur travail.

En terminant, je voudrais noter que les divergences de vue qui existent entre Lamonde et moi s'inscrivent dans le cadre des grands débats qui animent la profession historienne. Elles n'amoindrissent en rien mon respect et mon admiration pour Yvan Lamonde, historien et citoyen, ou son impressionnante œuvre historique.

Traduction: Michel Ducharme 